\title{
Vibration analysis and design of a structure subjected to human walking excitations
}

\author{
M. Setareh* and M. Lovelace \\ Virginia Polytechnic Institute and State University, Blacksburg, Virginia, USA
}

\begin{abstract}
Annoying building floor vibrations have become a serious serviceability issue. This is mainly due to decrease in the system mass resulting from the use of higher strength materials; use of computer-assisted design and the Load and Resistance Factor Design Method to optimize the structure based on the strength requirements; fewer partitions and more innovative designs by architects achieving long, column free spans resulting in a reduction in the natural frequency and damping. This paper provides details of the vibration analysis and design of a novel office building. Three-dimensional computer models of the structure were created and various modifications were made to the original structure, designed based on static loads, to reduce the possible excessive floor vibrations when subjected to walking excitations. Tuned mass dampers were also designed as a back-up vibration control system. A series of dynamic tests were conducted on the building floor to identify the dynamic properties of the structure and these were then used to update the original computer model. Finally, various forcing functions representing human walks and the updated computer model of the structure were used to evaluate the accuracy of the walking excitation force models to predict the structural response. Conclusions are made on the validity of each forcing function studied here.
\end{abstract}

Keywords: Serviceability problems, floor vibrations, tuned mass damper, human walk force model

\section{Introduction}

Building designers have in recent years been faced with excessive and annoying floor vibrations due to normal walking traffic occurring more frequently. One of the main causes of this problem is more innovative designs by architects in response to the tendency of the building owners to require long, column free spaces. To evaluate the susceptibility of building floors to such excitations, several design guides, standards and references recommend forcing functions in terms of general walk step frequencies. The acceleration response of the floor is usually compared with an acceptable limit to assess the vibration and the design of the structure. This paper presents various studies related to the analysis and design of an office floor susceptible to excessive floor vibrations, and it includes the results of the floor modal tests. It also uses four forcing functions defined in terms of the Fourier series of the walking step frequency, which are based on the recommendation of Bachmann, et al. [1], Murray, et al. [2], ISO 10137 [3] and Smith, et al. [4]. In addition, two measured-step forcing functions reported by Bachmann, et al. [1] and Khoncarly [5] are used for computer analysis of the structure to estimate the floor response and compare with the field measurements.

\section{Building description}

The structure used for this study is an office building located in Hudsonville, Michigan which serves as the headquarters for Lamar Construction Corporation. It consists of a steel structure with a total plan dimension of 134 $\mathrm{ft}-2$ in. $(40.9 \mathrm{~m})$ by $50 \mathrm{ft}-0$ in. $(15.2 \mathrm{~m})$, overhanging a garage and warehouse facility as shown in Fig. 1.

\footnotetext{
${ }^{*}$ Corresponding author. E-mail: setareh@ vt.edu.
} 


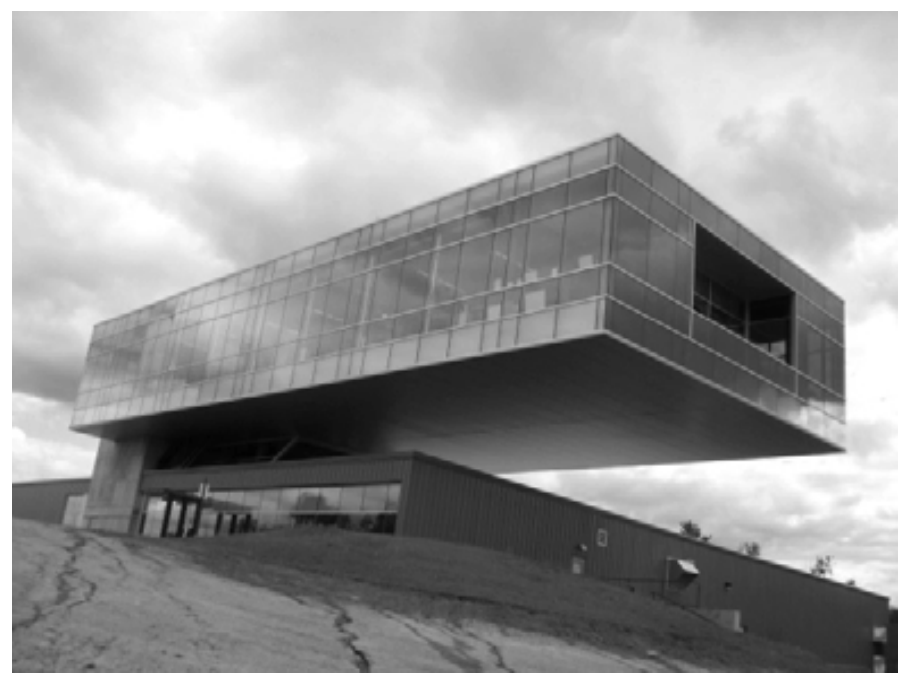

Fig. 1. The lamar construction headquarters, Hudsonville, Michigan.

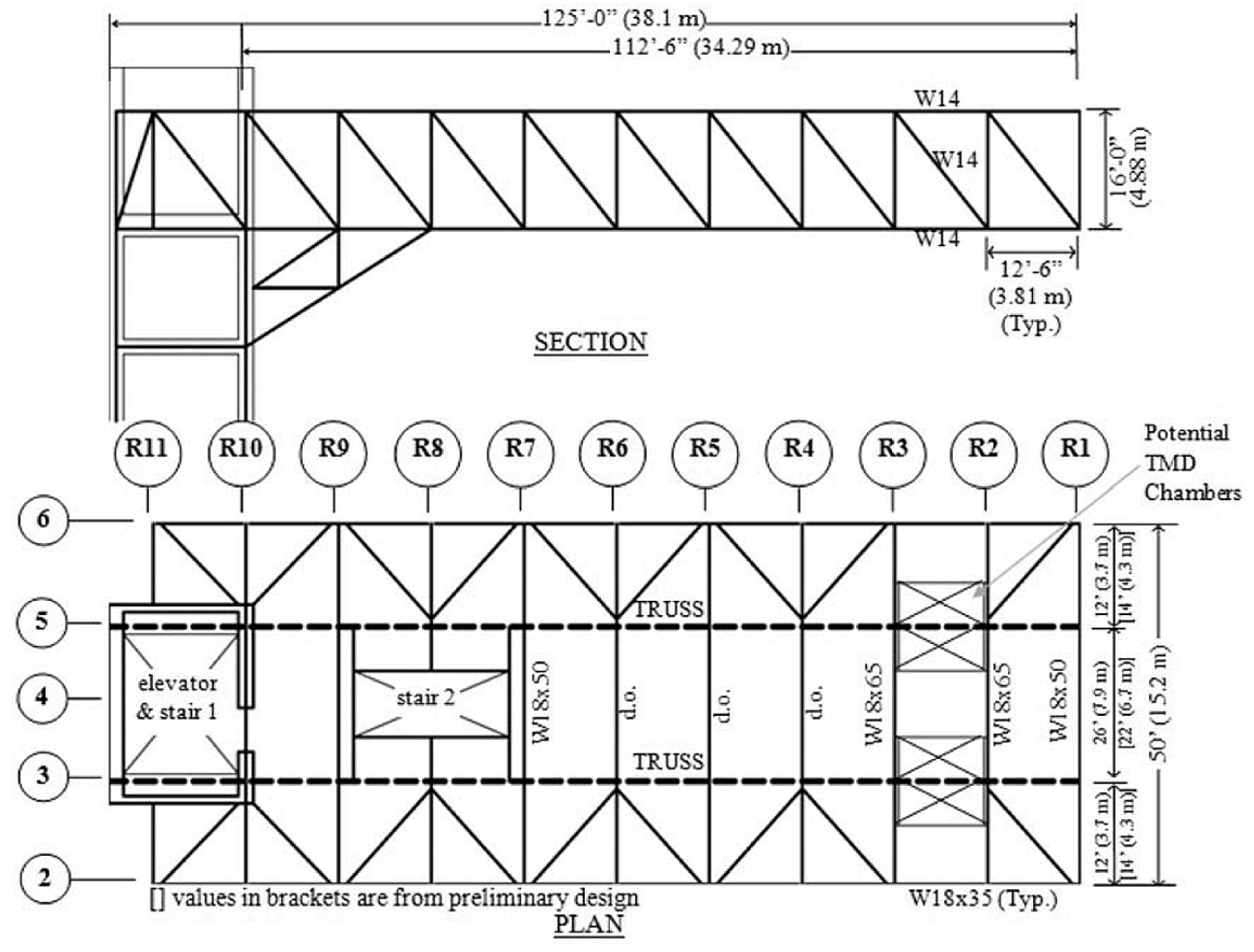

Fig. 2. Plan and section of the building.

The final configuration of the main supporting system consists of two $112 \mathrm{ft}-6 \mathrm{in}$. (34.29 m) long, $16 \mathrm{ft}-0 \mathrm{in}$. $(4.88 \mathrm{~m})$ deep cantilevered trusses, with the floor beams attached to the bottom flanges of the truss lower chord as continuous members as shown in Fig. 2. A 24 in. $(610 \mathrm{~mm})$ thick concrete core housing the elevator and a stair well provided structural stability. 


\section{Preliminary vibration analysis and design}

SAP2000 [6] computer software was used to create a three-dimensional computer model of the building structure based on the preliminary static design. Dynamic analyses of the structure resulted in the estimated natural frequencies of $1.90 \mathrm{~Hz}, 2.36 \mathrm{~Hz}$ and $3.24 \mathrm{~Hz}$, representing the torsional mode, vertical (bending) mode and the lateral (sway) mode, respectively. Since the range of normal walk speeds is about 1.6-2.3 steps per second [1], the first two modes of the structure were susceptible to excitations due to the first harmonics of the walking force. The third mode could only get excited by the second harmonics of the walking force.

The force was placed at the anti-nodes for the relevant modes (R1 and 2, Fig. 2). The walk forcing functions as recommended by Bachmann, et al. [1] in the form of Fourier series were used to compute the floor structure response:

$$
F(t)=G\left[1+\sum_{i=1}^{n} \alpha_{1} \sin \left(2 \pi i f t-\phi_{i}\right)\right]
$$

where $F(t)$ represents the walk forcing function, $t$ is the time, $G$ is the weight of the walker, $f$ is the excitation frequency in $\mathrm{Hz}, \alpha_{i}$ is the Fourier coefficient of the $i$-th harmonic, $\phi_{i}$ is the phase lag of the $i$-th harmonic relative to the first harmonic and $n$ is the total number of contributing harmonics. The average weight of a walker, $G$, was assumed to be $180 \mathrm{lb}$. (82 kg). Bachmann, et al. [1] recommend $\alpha_{1}=0.45 ; \alpha_{2}=0.1, \phi_{2}=\pi / 2 ;$ and $\alpha_{3}=0.1$ and $\phi_{3}=\pi / 2$.

A modal damping ratio of $2 \%$ was used and the excitation frequencies were set equal to the first and second mode natural frequencies of the structure to consider the most critical conditions. For the third mode, the excitation frequency was selected at one-half the natural frequency. The maximum vertical acceleration at the corner edge of the floor (R1 and 2, Fig. 2) was $1 \% \mathrm{~g}$, which was higher than the acceptable limit of about $0.5 \% \mathrm{~g}$ recommended by Murray, et al. [2] and the National Building Code of Canada [7].

\section{Final design analytical studies}

A number of modifications were made to raise the structure's natural frequencies thus making it less susceptible to excessive vibrations from walking. These included changes made in the orientation of the diagonal members of the trusses and increases in floor beams and truss member sizes. Also, the length of the cantilever portion of the floor beams was reduced from $14 \mathrm{ft}-0$ in. $(4.27 \mathrm{~m})$ to $12 \mathrm{ft}-0 \mathrm{in}$. ( $3.66 \mathrm{~m})$, and the span between the trusses was increased from $22 \mathrm{ft}-0$ in. $(6.70 \mathrm{~m})$ to $26 \mathrm{ft}-0$ in. $(7.92 \mathrm{~m})$ as shown in Fig. 2. A 12 in. $(305 \mathrm{~mm})$ high, raised floor was also added as part of the owner's requirements. The first four natural frequencies were $f_{1}=2.61 \mathrm{~Hz}$ (vertical mode), $f_{2}=3.41 \mathrm{~Hz}$ (lateral mode), $f_{3}=5.36 \mathrm{~Hz}$ (Torsional mode), and $f_{4}=7.32 \mathrm{~Hz}$ (local floor vertical mode). The mode shapes can be found in Setareh [8].

The computer model was subjected to the walking load excitations at the sub-harmonics of the natural frequencies of the structure since the floor natural frequencies were outside the normal range of walking speeds (1.6-2.3 steps/second). In addition, a walking excitation of $2.3 \mathrm{steps} / \mathrm{sec}$, the upper bound of a normal walk, was included. The force was applied at the corner edge of the floor (R1 and 2, Fig. 2) as an individual in-place marching excitation using Eq. (1). Assuming a $2 \%$ modal damping ratio, the maximum vertical and lateral accelerations were $0.26 \% \mathrm{~g}$ and $0.13 \% \mathrm{~g}$, respectively. These values are below the acceptable limits of $0.5 \% \mathrm{~g}$ for the vertical and $0.2 \% \mathrm{~g}$ for the lateral vibrations. However, based on the senior author's past experience, variation in the construction method may have resulted in changes in the structure natural frequencies and, therefore, higher accelerations could be expected. For this reason, the floor was subjected to a walking excitation at 2.6 steps/sec (representing brisk walks) to match the first mode natural frequency. This resulted in the maximum accelerations of $0.9 \% \mathrm{~g}$ and $0.05 \% \mathrm{~g}$ for the vertical and lateral directions, respectively. In this case, the vertical acceleration was well above the acceptable limit for office environments. Figure 3 shows the maximum floor vertical vibration responses when walking at 2.3 and 2.6 steps/sec. 


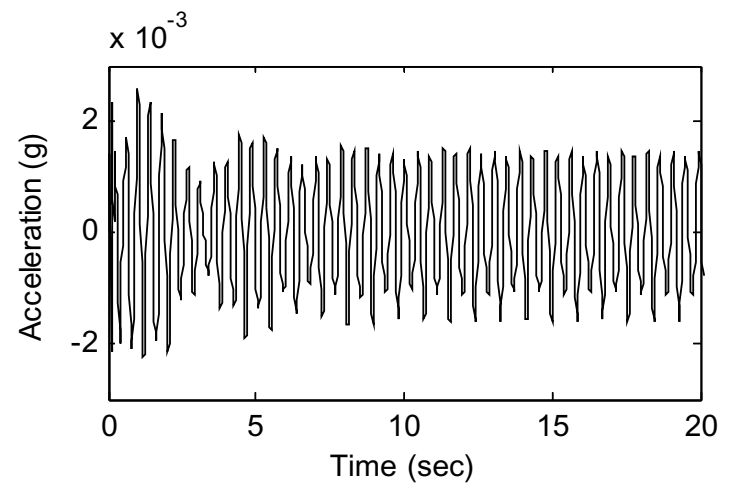

(a) walking at $2.3 \mathrm{steps} / \mathrm{sec}$

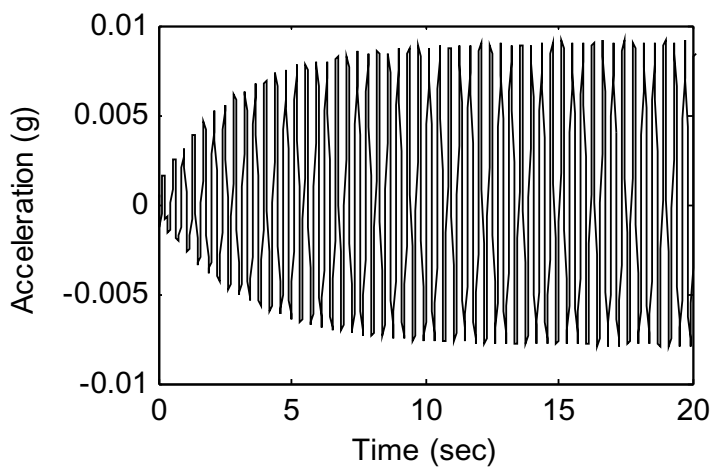

(b) walking at 2.6 steps $/ \mathrm{sec}$

Fig. 3. The floor maximum vertical acceleration vs. time response.

\section{Tuned mass dampers provisions}

Since there was still a possibility that the as-built floor system would have been susceptible to excessive walking vibrations even after the modifications to the structure, the decision was made to provide for the possible installation of tuned mass dampers (TMDs) within the raised floor plenum. The TMDs were designed to consist of weights, $8,000 \mathrm{lb}(3,600 \mathrm{~kg})$ in total, for tuning to the first and third modes which had the largest response contributions. It was determined that the extra TMD weights would not have resulted in any static overstressing of the structural members. The 4-2,000 lb (900 kg) option was adopted; however, the results were also applicable to the 2-4,000 lb $(1,800 \mathrm{~kg})$ configuration. With the effective mass ratio of 0.022 and 0.011 for the two modes, the optimum tuning frequency and damping ratios were: $f_{t}=0.993$ and $\xi=0.10$ for the first mode and $f_{t}=0.998$ and $\xi=0.067$ for the third mode.

Figure 4 shows the point accelerance FRF of the floor at the corner of the cantilever edge (R1 and 2, Fig. 2) before and after the TMDs installation. From this figure, it can be noted that the TMD placement can result in a reduction of about $72 \%$ in the first (bending) mode and $63 \%$ in the third (torsional) mode vibrations. The maximum level of vertical acceleration due to walking after the TMDs installation can also be reduced to about $0.3 \% \mathrm{~g}$, which is within the acceptable range.

\section{Modal testing}

A series of modal tests were conducted, both during the building construction and after its completion, to estimate the dynamic properties of the floor structure and possible needs for TMD installation. For these tests an electrodynamic shaker (APS Dynamics, Model 113), with an APS Model 114 amplifier and a number of accelerometers were used. An eight-channel Siglab Spectrum Analyzer (Spectral Dynamics, Model 20-84) was used to analyze and record the test measurements. A burst chirp excitation with a frequency bandwidth of $2-6 \mathrm{~Hz}$ was selected. A PCB 3701G capacitive accelerometer was attached to the shaker armature to measure the acceleration and compute input force. In addition, PCB 393C seismic accelerometers were used to measure the floor responses. Figure 5 shows the shaker, amplifier and the associated accelerometers.

The response records were analyzed using ME'scope VES [9] upon completion of the tests to identify the modal properties of the structure. Details of modal testing and analyses can be found in Setareh [8]. The estimated natural frequencies $(f)$ and modal damping ratios $(\xi)$ for the completed structure were: for the bending mode, $f_{1}=2.25 \mathrm{~Hz}$, $\xi_{1}=0.36 \%$; for the lateral/torsional mode, $f_{2}=2.54 \mathrm{~Hz}, \xi_{2}=1.1 \%$; and for the torsional mode, $f_{3}=2.99 \mathrm{~Hz}, \xi_{3}=$ $1.0 \%$. It can be noted that the measured damping ratios were less than the values used for the structural response prediction during the design phase. This can be attributed to the fact that the floor vibration was due to the global structural response, which did not result in the participation of non-structural elements such as full-height partitions. The results also showed that the structure natural frequencies were smaller than initially predicted, which was due 


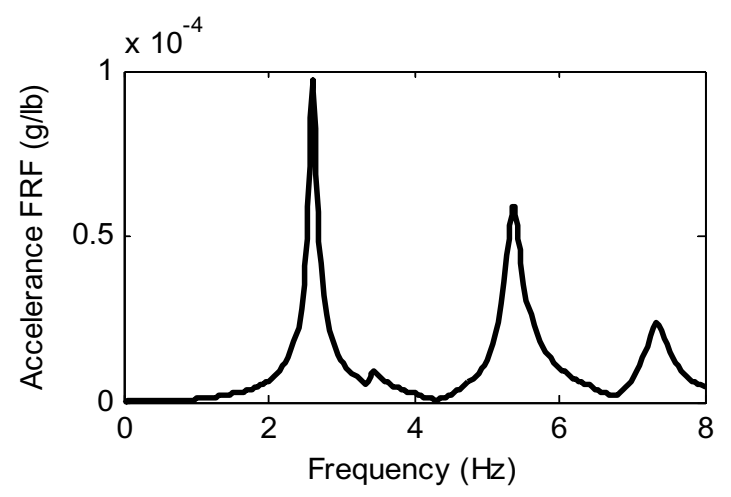

(a) without TMDs

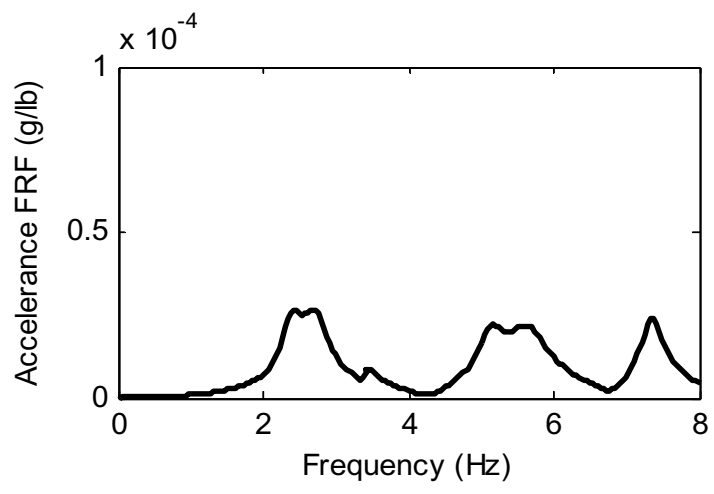

(b) with TMDs

Fig. 4. Floor point accelerance FRF at R1 and 2 without and with TMDs.

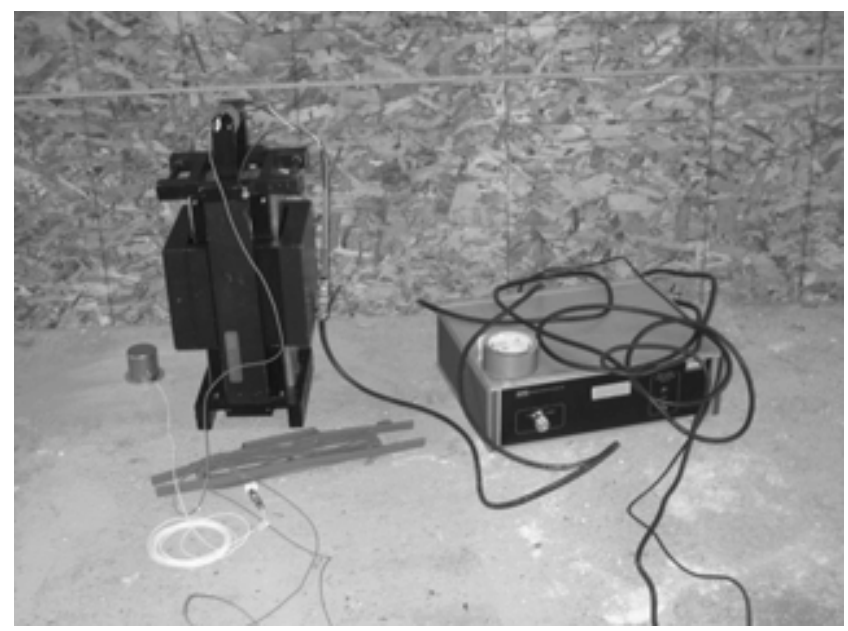

Fig. 5. Shaker, amplifier and accelerometers used for the modal testing.

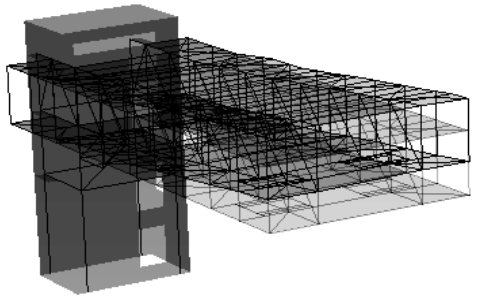

(a) $f_{l}=2.25 \mathrm{~Hz}$

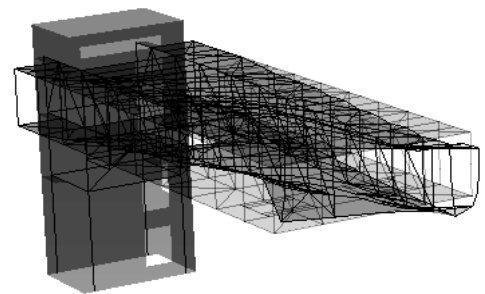

(b) $f_{2}=2.54 \mathrm{~Hz}$

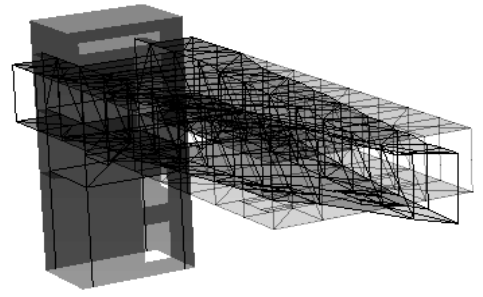

(c) $f_{3}=2.99 \mathrm{~Hz}$

Fig. 6. Measured mode shapes from the modal tests and analysis.

to the larger estimated stiffness and smaller mass of the curtain walls [8]. The structure mode shapes are shown in Fig. 6.

A number of controlled walks by an individual along the office corridor, located next to the trusses (see Fig. 2), were also conducted. The largest measured acceleration from these tests was about $0.67 \% \mathrm{~g}$ when the person walked at 2.25 steps/seconds as shown in Fig. 7. This is within the unacceptable range based on Murray, et al. [2] and NBCC [7]. However, evaluation and assessment of the vibration records based on other design guides and 
Table 1

Values of $\alpha_{i}$ and $\phi_{i}$ for the walking/jogging force excitations from different sources

\begin{tabular}{|c|c|c|c|c|c|c|c|}
\hline \multirow{2}{*}{\multicolumn{2}{|c|}{ Harmonic $(i)$}} & \multicolumn{2}{|c|}{ Bachmann, et al. [1] } & \multicolumn{2}{|c|}{ ISO 10137 [3] } & \multirow{2}{*}{$\begin{array}{l}\text { Murray, et al. [2] } \\
\text { Walking }\end{array}$} & \multirow{2}{*}{$\begin{array}{l}\text { Smith, et al. [4] } \\
\text { Walking }\end{array}$} \\
\hline & & Walking & Jogging & Walking & Jogging & & \\
\hline \multirow[t]{2}{*}{1} & $\alpha_{1}$ & 0.45 & 1.60 & $0.37(f-1.0)$ & 1.40 & $0.83 e^{-0.35 f}$ & $0.436(f-0.95)$ \\
\hline & $\phi_{1}$ & 0 & 0 & 0 & 0 & 0 & 0 \\
\hline \multirow[t]{2}{*}{2} & $\alpha_{2}$ & 0.10 & 0.70 & 0.10 & 0.40 & $0.83 e^{-0.70 f}$ & $0.006(f+12.3)$ \\
\hline & $\phi_{2}$ & $\pi / 2$ & 0 & 0 & 0 & 0 & $\pi / 2$ \\
\hline \multirow[t]{2}{*}{3} & $\alpha_{3}$ & 0.10 & 0.20 & 0.06 & 0.10 & $0.83 e^{-1.05 f}$ & $0.007(f+5.2)$ \\
\hline & $\phi_{3}$ & $\pi / 2$ & 0 & 0 & 0 & 0 & $-\pi$ \\
\hline \multirow[t]{2}{*}{4} & $\alpha_{4}$ & - & - & - & - & $0.83 e^{-1.40 f}$ & $0.007(f+2.0)$ \\
\hline & $\phi_{4}$ & - & - & - & - & 0 & $-\pi / 2$ \\
\hline
\end{tabular}

Note: Murray, et al. [2] and Smith, et al. [4] do not include values for the jogging/running.

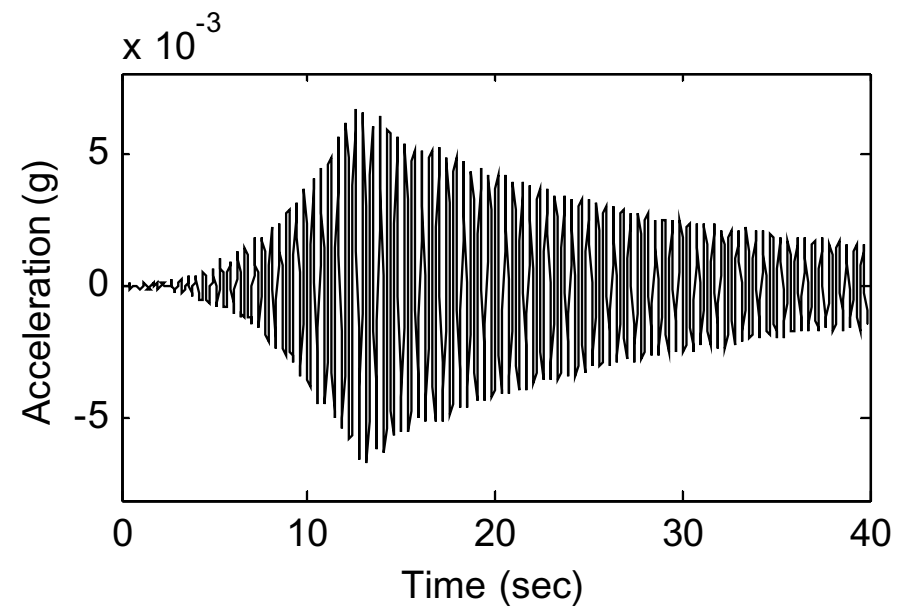

Fig. 7. Vertical acceleration response of location R1 and 2 when the individual walked at $2.25 \mathrm{steps} / \mathrm{sec}$.

standards proved this not to be the case [8]. Since the building was opened nearly three years ago, there have been no complaints from the occupants regarding possible annoying vibrations.

\section{Human walk force models}

The results of the modal testing and analysis were used to update the computer model of the structure. The first three natural frequencies of the updated model were $2.24 \mathrm{~Hz}, 2.74 \mathrm{~Hz}$ and $3.07 \mathrm{~Hz}$. Comparing these values with the results of the modal analysis mentioned above shows a maximum of $8 \%$ difference between the measured and computed natural frequencies.

The accuracy of four different walk force models defined in terms of the Fourier series of the step frequency in predicting the floor vibration response was evaluated. These forcing functions were recommended by Bachmann, et al. [1], Murray, et al. [2], ISO 10137 [3] and Smith, et al. [4]. All of these functions follow the relationship given in Eq. (1). Table 1 shows the values of the Fourier coefficient $\alpha_{i}$ and the phase lag, $\phi_{i}$, for various harmonics of the forcing functions from each source.

In addition, two measured force functions ([1] and [5]) were used. To better reflect the particular walks conducted on the structure, the frequency components of these forcing functions were adjusted [10]. Figures 8 and 9 show the resonance walk forcing functions, with step frequencies equal to each mode natural frequency, based on the Fourier series and measurements after adjustments, respectively. As can be noted, Fig. 8 shows the combined forces of two consecutive steps. However, Fig. 9 includes each step force in addition to the total force. For the first mode resonance walks (at 2.24 steps/sec), the peak force amplitudes from the measured Bachmann, et al. [1] and the Fourier-based 


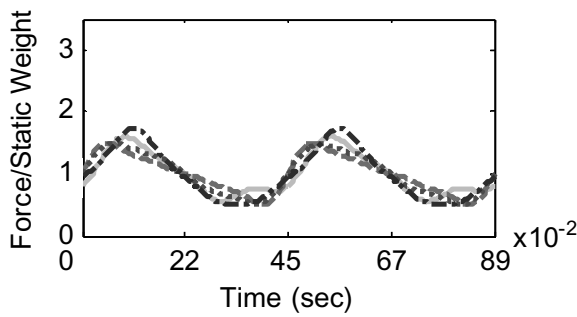

(a) Mode $1\left(f_{l}=2.24 \mathrm{~Hz}\right)$

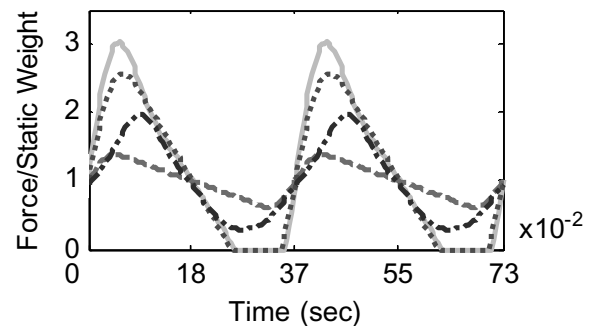

(b) Mode $2\left(f_{2}=2.74 \mathrm{~Hz}\right)$

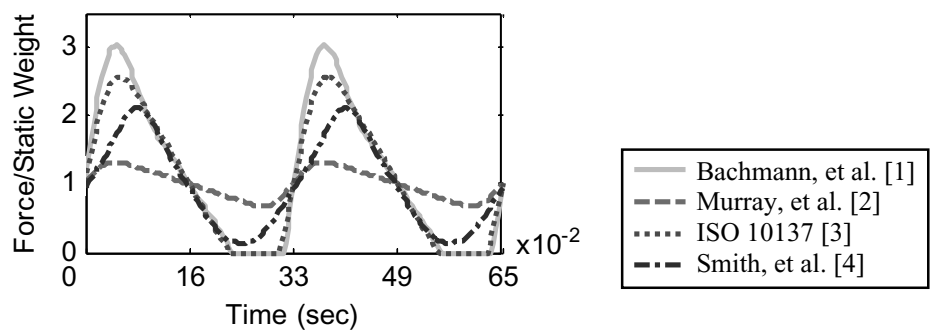

(c) Mode $3\left(f_{3}=3.07 \mathrm{~Hz}\right)$

Fig. 8. Resonance walk forcing function for each mode based on Fourier series.

forcing functions are close to each other. However, this is not the case for the second and third modes walk forcing functions. For the third mode walks, the Fourier-based Bachmann, et al. [1], ISO 10137 [3], and adjusted measured force of Khoncarly [5] represent a more realistic shape for the forcing function as they include loss of foot contact with the ground during a jog or very brisk walk.

Table 2 shows the percentage difference between the computer analysis and measured responses at different locations when the individual walked at the first, second and third mode frequencies. Locations 2, 4 and 6 are the vertical directions along lines R1 and 2, 4 and 6, respectively (see Fig. 2). Location 7 is the lateral direction at R1 and 6. The table also includes the expected differences between the computer analysis and measurements based on the comparison of the FRFs from the modal tests and the computer analyses [10].

For all cases, these results show that the measured adjusted walk models provided the best match with the measurements. This was expected as the adjustments were based on the modification of the frequency response of the forcing function. Amongst the Fourier series based forcing functions, Bachmann, et al. [1] and Murray, et al. [2] provided the best match for the first mode response. For the second mode, none of the Fourier based forcing functions provided an acceptable match. Finally, for the third mode the forcing function recommended by Smith, et al. [4] resulted in the best match between the computer analysis and the measurements among the Fourier based forcing functions.

\section{Summary and conclusion}

This paper presented a study of a long cantilevered, office building structure susceptible to walking vibrations. Various design modifications to reduce the vibration levels, in addition to the use of TMD passive control system, were presented. Results of the modal tests conducted after the completion of construction were presented. This showed a large discrepancy between the assumed and measured damping levels. The low level of the measured damping can be attributed to the fact that floor response was the result of the structure global dynamic behavior rather than the local deck vibrations. Using the results of the test measurements, the computer model of the structure was updated. Several different walking force functions were used to measure the floor response and were compared with the measurements. It was observed that in each case the adjusted measured walk model provided the best match with the measurements. The forcing functions recommended by Bachmann, et al. [1] and Murray, et al. [2] provided the best match when the first mode was excited. For the third mode excitation, Smith, et al. [4] resulted in the best match with the measurements among the Fourier series based forcing functions. 
Table 2

Comparison of the responses from the computer analysis vs. measurements for different walk forcing functions at different resonance step frequencies

\begin{tabular}{|c|c|c|c|c|c|c|c|c|}
\hline \multirow[t]{3}{*}{ Mode } & \multirow[t]{3}{*}{ Location } & \multirow{3}{*}{$\begin{array}{c}\text { Expected } \\
\text { Difference }(\%)\end{array}$} & \multicolumn{6}{|c|}{ Difference of Analysis vs. Measurement (\%) } \\
\hline & & & \multicolumn{2}{|c|}{ Adjusted Measured Walk Model } & \multicolumn{4}{|c|}{$\begin{array}{l}\text { Fourier Series Equation } \\
\end{array}$} \\
\hline & & & Khoncarly [5] & $\begin{array}{c}\text { Bachmann, } \\
\text { et al. [1] }\end{array}$ & $\begin{array}{c}\text { Bachmann, } \\
\text { et al. [1] }\end{array}$ & ISO $10137[3]$ & $\begin{array}{l}\text { Smith, } \\
\text { et al. [4] }\end{array}$ & $\begin{array}{l}\text { Murray, } \\
\text { et al. [2] }\end{array}$ \\
\hline \multirow[t]{2}{*}{1} & 2 & -2.7 & -3.3 & -3.0 & +17 & +29 & +44 & +16 \\
\hline & 4 & -8.9 & -10 & -9.9 & +9.2 & +20 & +33 & +7.9 \\
\hline \multirow[t]{2}{*}{2} & 2 & +2.4 & +1.9 & +2.9 & +396 & +368 & +221 & +89 \\
\hline & 7 & +35 & +62 & +64 & +690 & +645 & +411 & +201 \\
\hline \multirow[t]{2}{*}{3} & 2 & -0.64 & -1.3 & -1.2 & +28 & +21 & -5.8 & -54 \\
\hline & 6 & -0.70 & -3.9 & -11 & +22 & +15 & -11 & -56 \\
\hline
\end{tabular}
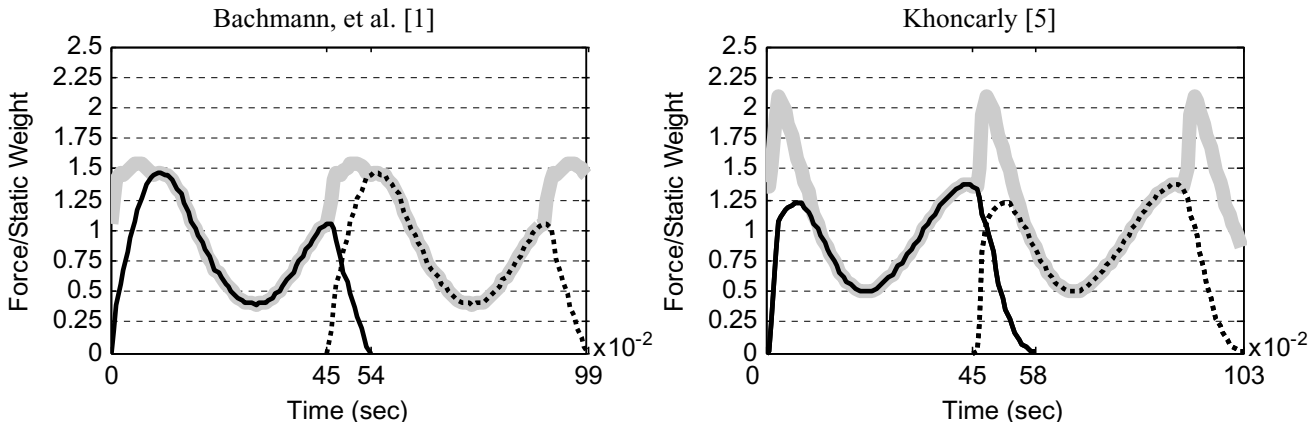

(a) Mode $1\left(f_{l}=2.24 \mathrm{~Hz}\right)$
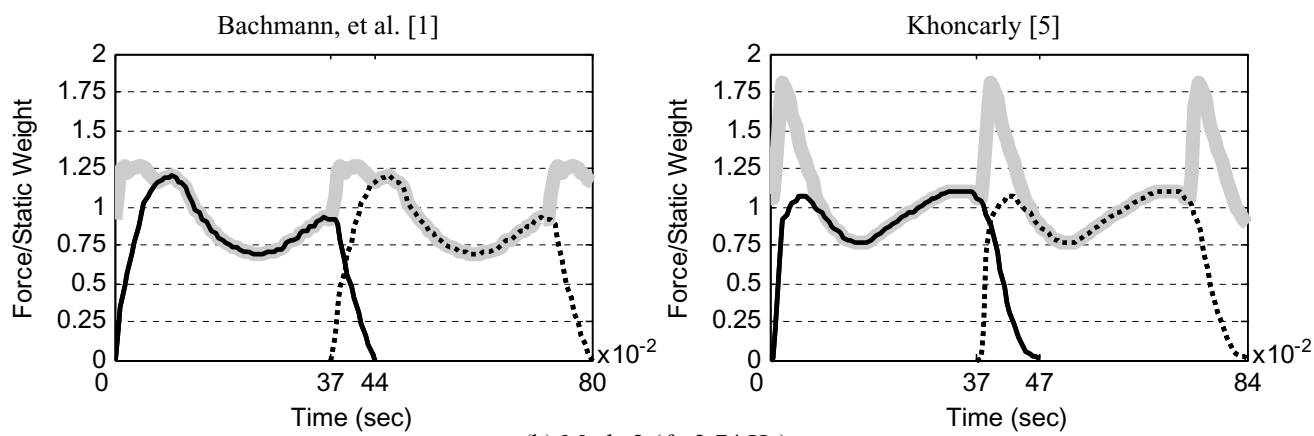

(b) Mode $2\left(f_{2}=2.74 \mathrm{~Hz}\right)$
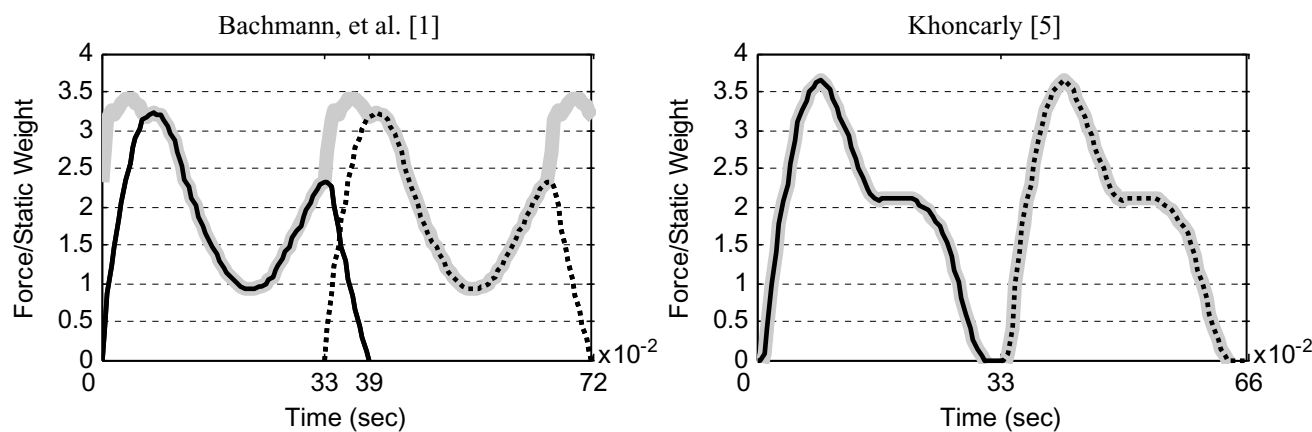

(c) Mode $3\left(f_{3}=3.07 \mathrm{~Hz}\right)$

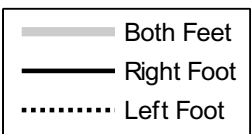

Fig. 9. Resonance walk forcing functions for each mode based on measurement 


\section{Acknowledgements}

The study presented here was supported by the National Science Foundation under grant No. CMMI-0324471. This support is gratefully acknowledged. Any opinions, findings, and conclusions expressed in this paper are those of the authors and do not necessarily reflect the view of the National Science Foundation. Contribution and cooperation of Structural Design, Inc. and in particular Mr. Paul Dannels are greatly appreciated.

\section{References}

[1] H. Bachmann et al., "Vibration Problems in Structures: Practical Guidelines", Birkläuser Verlag, Basel, Switzerland, 1995.

[2] T.M. Murray, D.E. Allen and E.E. Ungar, Floor Vibrations Due to Human Activities, Steel Design Guide Series-11, AISC/CISC, 1997.

[3] ISO 10137, Bases for Design of Structures-Serviceability of Buildings and Walkways against Vibrations-ISO 10137, International Organization for Standardization, Geneva, Switzerland, 2007.

[4] A.L. Smith, S.J. Hicks and P.J. Devine, "Design of Floors for Vibration: A New Approach", The Steel Construction Institute, Ascot, Barkshire, UK, 2007.

[5] M.M. Khoncarly, "Dynamic Response of Floor Systems to Footfall-Induced Vibrations", PhD Thesis, Case Western Reserve University, Cleveland, Ohio, 1997.

[6] CSI, "SAP2000 - Static and Dynamic Finite Element Analysis of Structures," Version 11.0.8, Computers and Structures, Inc., Berkeley, California, 2007.

[7] NBCC, "Users' Guide - National Building Code of Canada: Structural Commentaries - Commentary D: Deflection and Vibration Criteria for Serviceability and Fatigue Limit States, Canadian Commission on Building and Fire Codes", National Research Council of Canada, Ottawa, Ontario, Canada, 2005.

[8] M. Setareh, "Floor Vibration Serviceability Studies, College of Architecture and Urban Studies", Virginia Tech, Blacksburg, Virginia, 2009.

[9] Vibrant Technology, Inc., "ME'scope VES 5.0," Scotts Valley, California, 2008.

[10] M. Lovelace and M. Setareh, "Vibration Studies of an Office Building", College of Architecture and Urban Studies, Virginia Tech, Blacksburg, Virginia, 2009. 

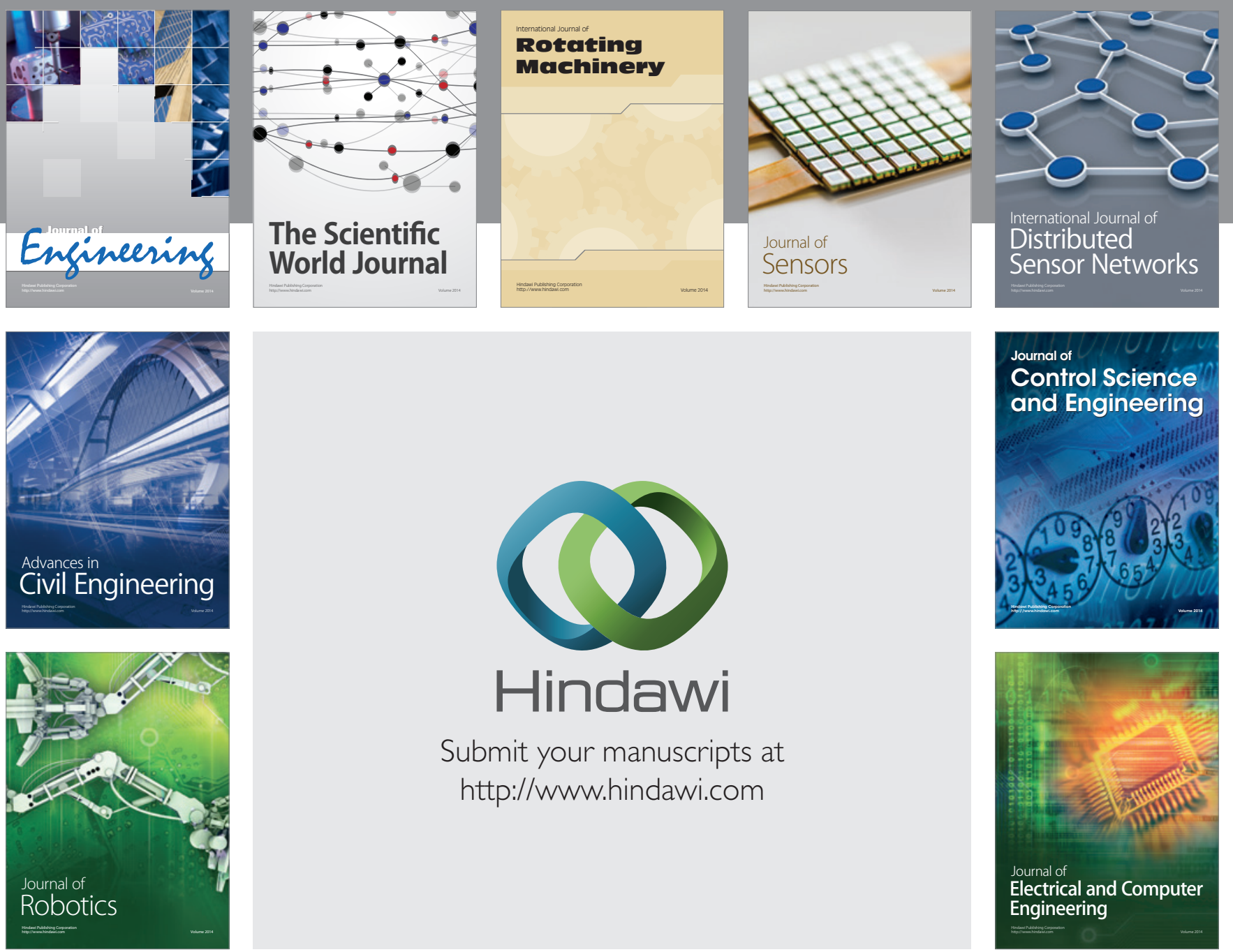

Submit your manuscripts at

http://www.hindawi.com
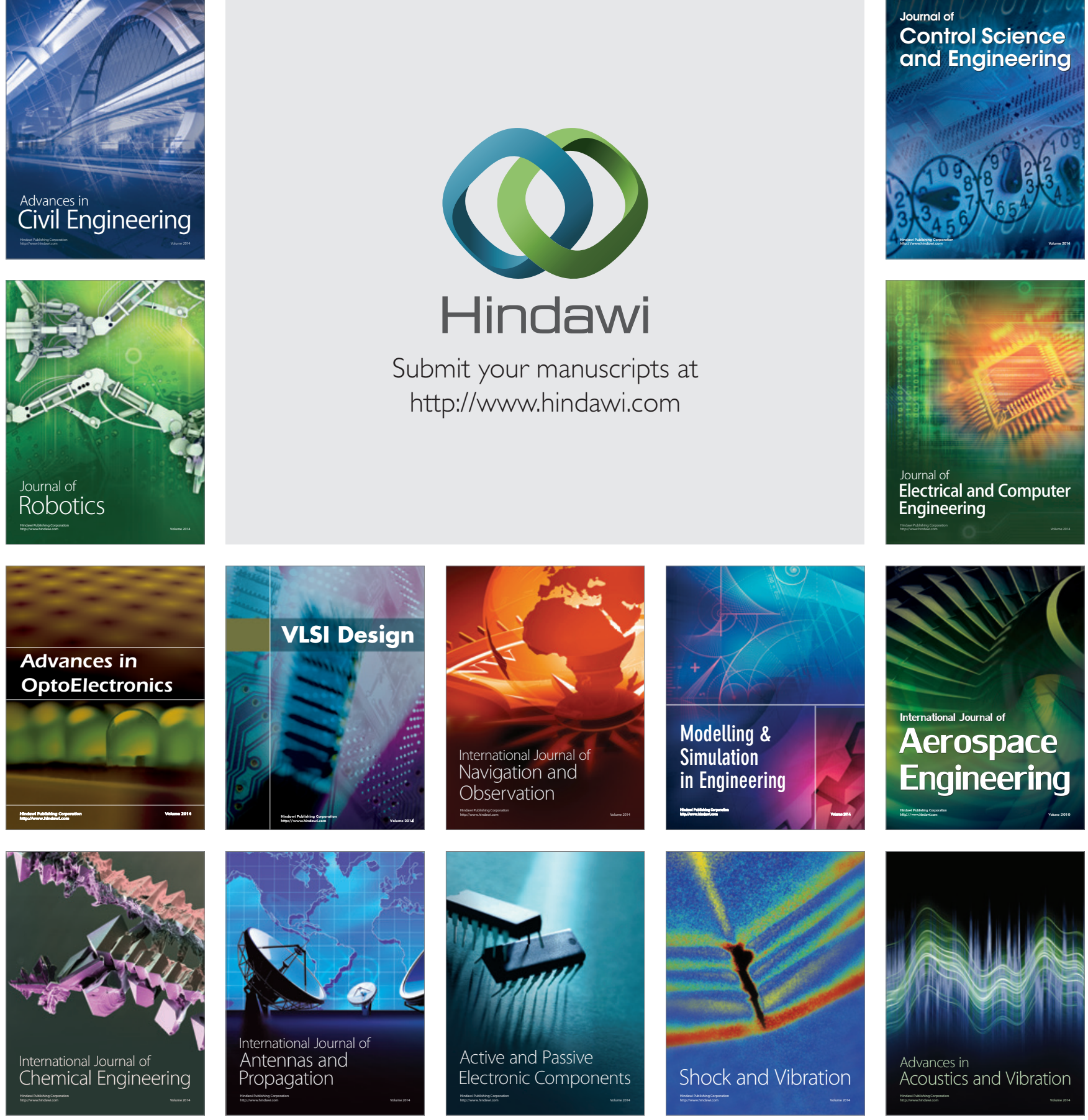